\title{
Adaptive Droop for Control of Multiterminal DC Bus Integrating Energy Storage
}

\author{
Catalin Gavriluta, Student Member, IEEE, J. Ignacio Candela, Member, IEEE, Joan Rocabert, Member, IEEE, \\ Alvaro Luna, Member, IEEE, and Pedro Rodriguez, Fellow, IEEE
}

\begin{abstract}
Multiterminal de (MTDC) systems are drawing a lot of interest lately in applications related to distributed generation, especially in those that integrate wind or photovoltaic (PV) generation with energy storage (ES). Several approaches for controlling the operation of such systems have been proposed in the literature; however, the existing structures are mainly application specific and, thus, can be still improved in order to provide a more generic approach. This paper proposes an improved primary control layer for an MTDC system. The concept is based on the combination of a droop control method and dc bus signaling in order to provide a more generic and flexible solution. In this paper, different droop characteristics are proposed for the various elements connected to the dc bus. All of them are specifically tailored around five operation bands, which depend on the dc bus voltage level. Special attention is paid to the integration of ES: the state of charge $(\mathrm{SoC})$ is considered at the primary control level, yielding a surface characteristic that depends on the $\mathrm{SoC}$ and the dc bus voltage. The scaling of the system has been analyzed together with the proposed control strategy and the overall operation has been validated through simulations by considering a $100 \mathrm{~kW}$ PV system with energy storage. Experimental results were obtained on a scaled laboratory prototype rated at $10 \mathrm{~kW}$.
\end{abstract}

Index Terms-Distributed generation, droop control, energy storage, MTDC systems, parallel connection of converters.

\section{INTRODUCTION}

C HALLENGES related to the integration of remote generation, together with recent advances in power electronics and voltage-source converters (VSC), have reignited the interest toward MTDC [Please define "MTDC"] networks. According to the literature [1], MTDC seems to be the most feasible solution for the problem of long-distance power transmission. Since offshore wind farms are facing this exact challenge, the topic has been extensively approached in the last few years. Various topologies and control algorithms for such systems are presented in [2]-[7]. Also, studies regarding stability [8]-[10], protection [11]-[15], and interaction with the conventional ac grids [16]-[19] can be found in the literature.

Even though the topic of MTDC for the integration of offshore wind farms is the most approached topic in the area, other

Manuscript received August 22, 2013; revised March 19, 2014; accepted August 07, 2014. Paper no. TPWRD-00959-2013.

The authors are with the Department of Electrical Engineering, Technical University of Catalonia, Terrassa, Barcelona 08222, Spain IPlease provide e-mail address].

Digital Object Identifier 10.1109/TPWRD.2014.2352396 authors have started to analyze the benefits of MTDC grids in other applications. According to [20] and [21], a modular PV system, based on a common dc bus that enables the integration of ES and dc loads, could be the ideal solution for future microgrid applications. This system could offer advantages in terms of efficiency, reliability, and scalability.

The main control challenge in MTDC systems is the regulation of the dc voltage. The dc voltage is directly related to the power flow between the elements of the dc network, similar to the frequency in ac grids. As underlined in [22], there are two options for implementing such a control strategy. The first one is based on a centralized controller that monitors the entire system through an external communication link and optimally dispatches the loads and the sources. A centralized system has the advantage of being optimal, but the dependence on external communication is a serious drawback.

As an alternative to the centralized structure, there are the so-called decentralized control strategies, including master slave, droop, and dc bus signaling methods [22].

Since at the present time there are no specific standards that regulate the operation of dc grids, various application-specific approaches, based on combinations of droop and master-slave controllers are found in the literature, as [23]-[26].

A more robust approach can be achieved by combining the two previously described control methods in a hierarchical structure. In the attempt to standardize the control and management of dc grids, such an approach is described in [27]. Here, the primary layer of control is local and decentralized, while the upper layers, based on low-bandwidth communication, manage the system. This control strategy is similar to the well-known hierarchical control of frequency in ac grids and incorporates the advantages of centralized and decentralized control.

At the moment, energy storage in the context of MTDC networks is scarcely approached. However, since the grid codes are becoming more demanding, integration of energy storage in renewable power plants will be unavoidable if services, such as frequency control or load following, were to be required.

Sustaining the ideas of hierarchical control and of a standardized approach in controlling MTDC networks, this paper proposes and validates a primary control strategy built around the concept of integrating energy-storage elements into MTDC grids. The energy-storage elements play a key role in the power-flow balancing; therefore, the variation of the $\mathrm{SoC}$ is taken into account when designing the control strategy. In this way, a protection mechanism against the overcharge and deep discharge of the battery are included in the primary control and, 
moreover, as will be seen in the following sections, the dc bus voltage becomes correlated with the overall remaining energy reserves of the network.

Even though it has the integration of energy storage at its core, the solution that is proposed in this paper is not limited to this type of application. The control strategy that we proposed is based on droop control and dc bus signaling, making for a generic approach where each droop curve is tailored around five operating bands, hence, providing modularity and extendability to the system.

This paper is organized as follows: Section II provides a detailed description of the overall concept while Section III provides an analysis regarding the control of one element of the system. Sections IV and V present simulation and experimental results in order to validate the proposed concept and Section VI presents the conclusions.

\section{SYSTEM DESCRIPTION}

A conceptual system suitable for the control of a PV power plant with multiple ES units is sketched in Fig. 1. Here, several power converters are connected to a common dc bus, forming a basic multiterminal de network with multiple connections to the ac grid. For illustration purposes, two different connection types with the ac system are shown. As it will be seen in the following sections, one is critical (converter 4) and is suitable for connections to weak grids, while the other (converter 2) allows for a more flexible connection. A hierarchical control structure would be the best choice for control and safe operation of such a system. In this type of control strategy, the lowest control level, namely, the primary control, is implemented locally in each converter and has to operate independently without making use of external communication channels. The dc bus voltage level can be used as a global decision parameter, and control actions can be locally taken based on this value. The secondary control layer is implemented as a centralized controller and based on measurements from all of the connected units, should act like an energy-management system and operation optimizer by setting the appropriate references to the primary control.

This paper focuses on the design of primary control. In order to satisfy the requirements imposed on this layer of control, we propose that each converter should be controlled by custom droop characteristics tailored by taking into account the power balance of the network which, in dc networks, is reflected in the voltage amplitude. For this, five operating bands are defined for the network voltage. The normal operation (NO) band is the voltage interval for which the system is considered to be under standard operation, and the balance between load and production is satisfied. The NO band is surrounded by two safety bands; one in the lower part (SL) and one in the higher (SH). These bands are considered for the cases of transients or other sudden events that deflect the dc bus voltage from the NO region. Finally, a critical high $(\mathrm{CH})$ band and a critical low (CL) band are considered. When the voltage reaches these bands, there is a mismatch between production and consumption that can no longer be supported by the storage elements.

Before analyzing each of the droop characteristics, a convention for the sign of the currents has to be set. Throughout this paper, a positive current on the dc bus side is considered to be a

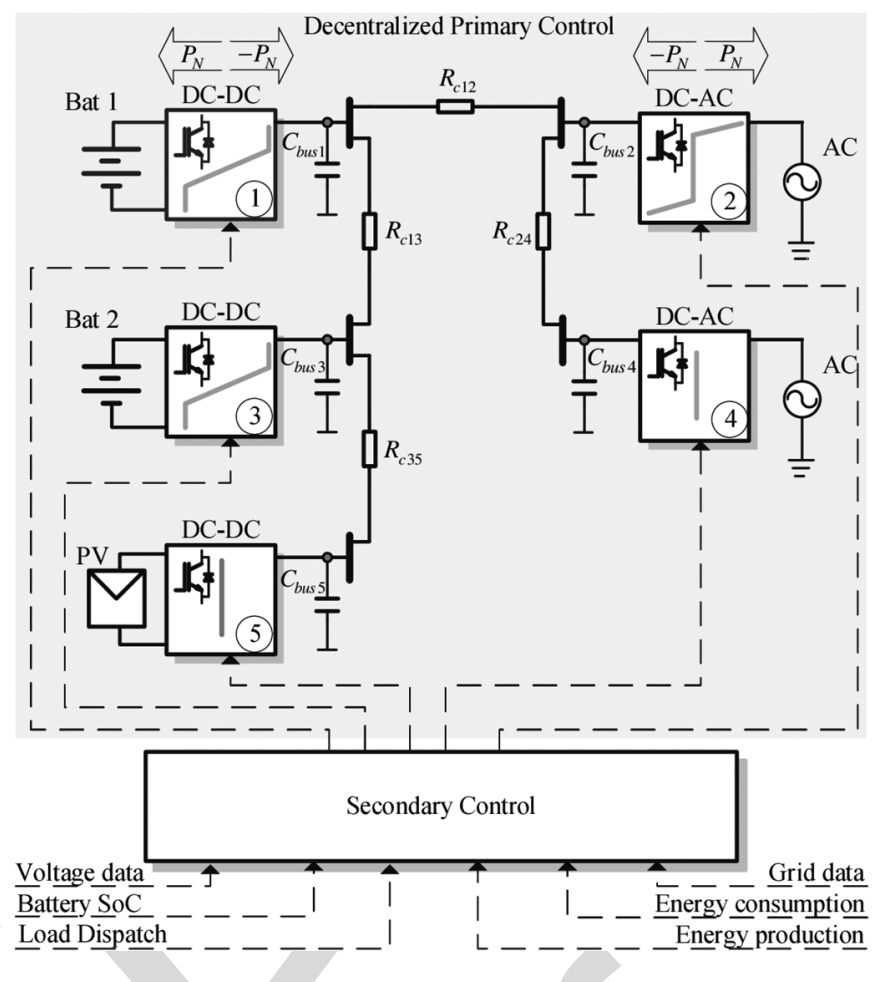

Fig. 1. Conceptual view of the control and management of the common dc bus system.

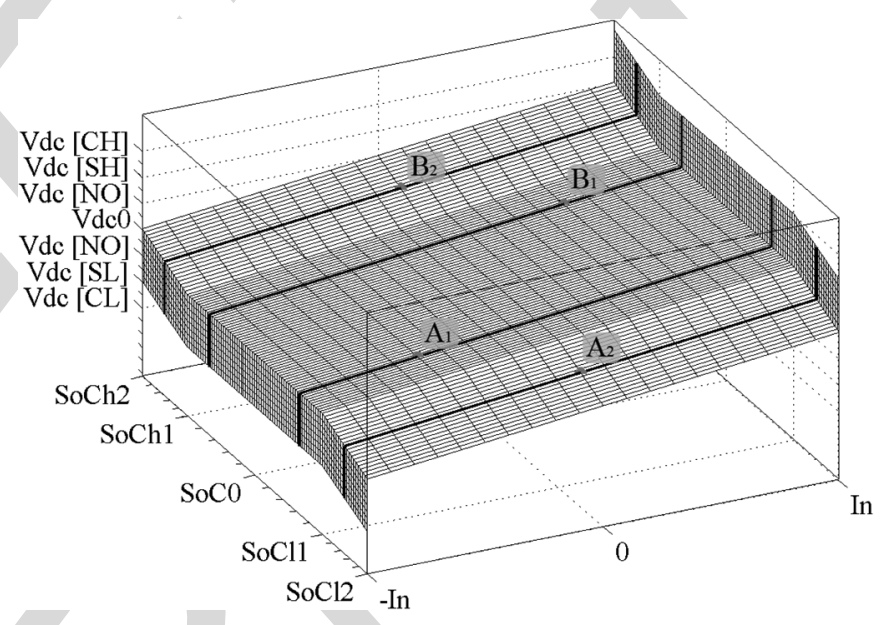

Fig. 2. Droop surface for energy-storage elements.

load current that is being drained from the dc bus. On the other hand, negative current is considered to be injected into the $\mathrm{dc}$ grid as seen on the top of Fig. 1

$$
V_{\mathrm{dc}}^{0}=\left\{\begin{array}{l}
V_{\mathrm{dd}}^{n}, \\
\quad \text { if } S o C \in\left[S o C_{l 1}, S o C_{h 1}\right] \\
\min \left(\frac{S o C-S o C_{h 1}}{S o C_{h 2}-S o C_{h 1}} \cdot\left(V_{\mathrm{dc}}^{c h}-V_{\mathrm{dc}}^{n}\right)+V_{\mathrm{dc}}^{n}, V_{\mathrm{dc}}^{c h}\right) \\
\quad \text { if } S o C \geq S o C_{h 1} \\
\max \left(\frac{S o C-S o C_{l 2}}{S o C_{l 1}-S o C_{l 2}} \cdot\left(V_{\mathrm{dc}}^{n}-V_{\mathrm{dc}}^{c l}\right)+V_{\mathrm{dc}}^{c l}, V_{\mathrm{dc}}^{c l}\right) \\
\quad \text { if } S o C \leqslant S o C_{l 1} .
\end{array}\right.
$$

The droop surface presented in Fig. 2 is proposed for the control of the converter connected to batteries. The definition of this droop characteristic starts by fixing its slope and the nominal 


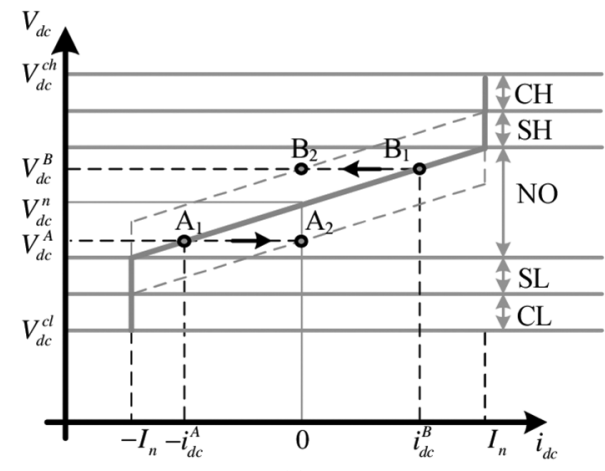

(a)

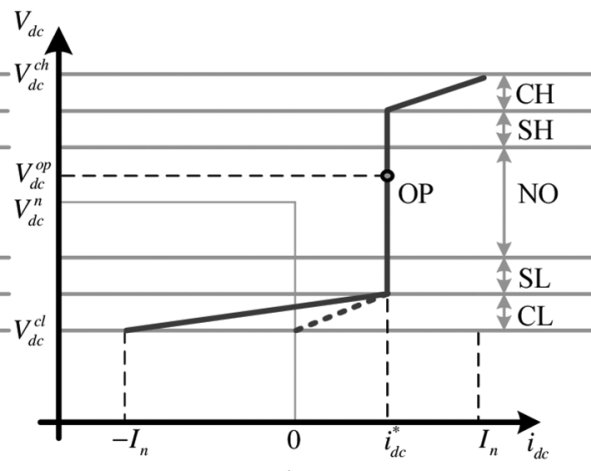

(b)

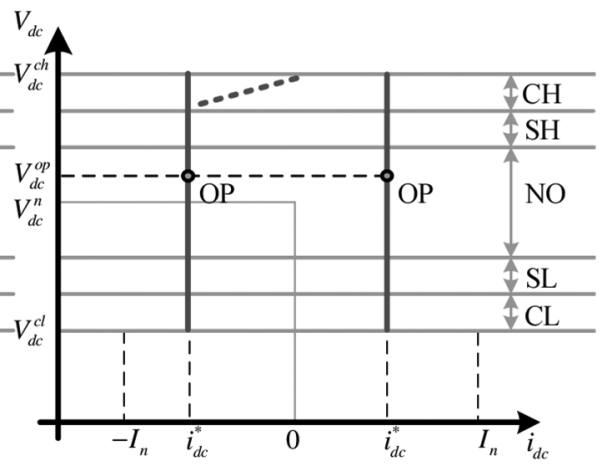

(c)

Fig. 3. Proposed droop type: (a) droop characteristic for the bidirectional noncritical element, (b) droop characteristic for bidirectional (solid line) and unidirectional (dotted line) pseudo-critical element, and (c) droop characteristic for the critical load and source (solid line) and pseudocritical source (dotted line).

current $I_{n}$. Then, the voltage level for which the converter injects zero current, namely, the operating point $\left(V_{\mathrm{dc}}^{0}, 0\right)$ has to be defined. The amount of current a battery is able to deliver or absorb is directly linked to its SoC. By linking the SoC with $V_{\mathrm{dc}}^{0}$, as shown in (1), the droop characteristic becomes a surface defined by $\mathrm{SoC}$ and the de voltage, as shown in Fig. 2. From the terms present in (1), $V_{\mathrm{dc}}^{n}$ is the nominal voltage of the network, while $V_{\mathrm{dc}}^{c h}$ and $V_{\mathrm{dc}}^{c l}$ are the maximum and minimum voltage levels. The $S o C-V_{\mathrm{dc}}$ droop-surface was designed to include, at the primary control level, a protection mechanism against the overcharge and deep discharge of the battery. In order to avoid overcharge, a high state of charge band $\left[S o C_{h 1}, S o C_{h 2}\right]$ is defined, while $\left[S o C_{l 1}, S o C_{l 2}\right]$ is defined in order to avoid the deep discharge of the battery.

Fig. 3(a) shows a cross-section of the $S o C-V_{\text {dc }}$ droop surface. Two operating scenarios, also shown in Fig. 2, are highlighted here. In the first one, the converter connected to the battery operates at point $A_{1}$, discharging the battery at a rate equal to $-i_{\mathrm{dc}}^{A}$. As the discharge continues, the SoC reaches $S o C_{l 1}$. According to Fig. 2, at this point, the converter starts to linearly shift its droop characteristic downwards, limiting the amount of power extracted from the battery. If there are other elements in the network that can compensate for this reduction in power, then $V_{\mathrm{dc}}$ will remain at the same level and the converter will reach $A_{2}$ where no more current is allowed to be drawn from the battery, as seen in Fig. 3(a). In the case that there are no other elements to compensate for the reduction in power, then, as will be seen in the simulation and experimental results, $V_{\mathrm{dc}}$ will linearly decrease and will enter the CL operating band. In both cases, the SoC of the battery will not decrease below $S o C_{l 2}$, therefore ensuring protection against deep discharge.

The second operating scenario starts with the converter operating at point $B_{1}$, charging the battery with a current equal to $i_{\mathrm{dc}}^{B}$. Similar to the previous scenario, as the charging continues, the SoC reaches $S o C_{h 1}$ and the converter starts to push its droop characteristic upwards, as seen in Fig. 2. If the dc bus voltage is maintained at the same level, the converter reaches $B_{2}$ where it reduces the current injected into the battery to zero. As before, the dependence of the droop surface on the $\mathrm{SoC}$ and $V_{\mathrm{dc}}$ will never allow for the SoC of the battery to increase above $\mathrm{SoC}_{h 2}$.

Fig. 3(b) presents the characteristic for the pseudocritical elements. These elements operate as constant current sources if the

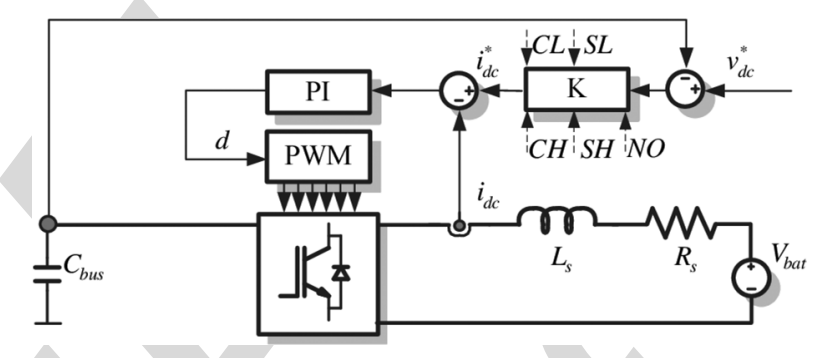

Fig. 4. Control block diagram for one element connected to the common dc bus system.

voltage is within the $\mathrm{NO}$ and safety regions. Once the system reaches the critical bands, they reduce or increase their demand in order to maintain the power balance of the system. The bidirectional (solid line), allows for the current to flow in the opposite direction for critical scenarios. This could be used to control a converter that connects to a neighboring network with which there is a power delivery contract. The unidirectional characteristic (dotted line) does not allow for current inversion, and could be employed by a load system, such as heating units, that can reduce or increase its power consumption if the dc bus level reaches critical levels.

Fig. 3(c) presents the droop characteristic of the critical elements. This kind of element, regardless if it behaves as a load or source, will not reduce its output even when the dc bus is in the critical bands. Since most of the generators can safely reduce their power output if needed, a small variation (dotted line) was introduced for the critical generators. Renewable energy plants, such as PV or wind systems that employ some maximum powerpoint tracking capability, would typically interface with the network through one of these connections.

\section{Control System AND Tuning}

The block diagram depicted in Fig. 4 presents the proposed electrical configuration and control structure for the dc side of a single element of the system presented in Fig. 1. As can be seen, the proposed structure is comprised of two loops: 1)an internal current control loop, based on a PI controller, and 2) an outer voltage loop, controlled through one of the droop curves previously presented. 
In order to analyze the scaling and design of the system, a boost dc-dc converter connected to a battery was chosen as a study case. The starting point of the analysis is the definition of the main parameters to be used in the control of the converter, namely: $P_{n}$-nominal power of the converter [W], $V_{\mathrm{dc}}$ - nominal voltage of the dc bus [V], $V_{\mathrm{bat}}$-voltage of the battery $[\mathrm{V}], f_{s}$-switching frequency $[\mathrm{Hz}], \Delta I_{L}$-allowable ripple in the dc current [A], and $\Delta V_{\mathrm{dc}}$-allowable ripple in the dc bus voltage $[\mathrm{V}]$.

According to [28], in order to fulfill the required current and voltage ripple, the passive elements of the converter, mainly the filter inductor and the dc bus capacitor, have to be calculated as follows:

$$
C_{\mathrm{bus}}=\frac{I_{n} \cdot d \cdot T_{s}}{\Delta V_{\mathrm{dc}}}, \quad L_{s}=C_{\mathrm{bus}} \frac{V_{\mathrm{dc}} \cdot d \cdot(1-d) \cdot T_{s}}{\Delta I_{L}}
$$

where $d=V_{\mathrm{dc}}-V_{\mathrm{bat}} / V_{\mathrm{dc}}$ is the duty cycle, $T_{s}=1 / f_{S}$ is the switching period, and $I_{n}=P_{n} / V_{\mathrm{dc}}$ is the nominal current of the converter.

\section{A. Tunning of the Controller}

It can be shown that the current control loop of the converter can be properly shaped so that it can be approximated with a low-pass filter in closed-loop form. For example, this can be achieved if the design criteria for a PI controller proposed in [29] is followed. This methodology designs the gains of the controller based on the value of the passive elements of the converter and on the imposed values of bandwidth and phase margin.

Once the current controller has been properly designed, it can be approximated by a low-pass filter with the cutoff frequency equal to $\omega_{c l}$ in order to reduce the order of the overall system.

Taking into account the droop gain $K$ and the dc bus capacitor $C_{\text {bus }}$, together with the current loop, the expression of the outer (voltage) open-loop transfer function is obtained as shown

$$
H_{v}(s)=\frac{K \cdot \omega_{c l}}{s \cdot C_{\mathrm{bus}}\left(s+\omega_{c l}\right)} .
$$

In order to determine a relationship between the droop gain, the size of the dc bus capacitor and the speed of the inner current loop, the open-loop bandwidth of the voltage transfer function is calculated by solving $\left|H_{v}(j \omega)\right|=1$. The result of this equation is presented as

$$
\omega=\sqrt{\frac{\sqrt{\omega_{c l}^{4} \cdot C_{\mathrm{bus}}^{2}+4 \cdot K^{2} \cdot \omega_{c l}^{2}}-\omega_{c l}^{2} \cdot C_{\mathrm{bus}}}{2 \cdot C_{\mathrm{bus}}}} .
$$

The theory of cascaded control recommends that the inner loop should be around six times faster than the outer loop in order to have a stable system

$$
\omega<\frac{\omega_{c l}}{\alpha} .
$$

Considering the speed ratio between the inner and outer loop as expressed in (4), and solving (3) for $K$, then the relationship expressed in (5) can be obtained. This relation shows how the

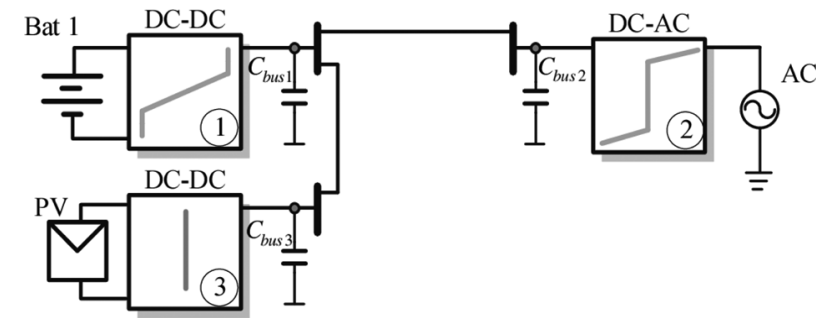

Fig. 5. Block diagram of Simulation Scenario 1. Basic system composed of a bidirectional ES, one critical PV generator, and one pseudocritical ac grid connection.

chosen speed of the outer loop and the size of the dc bus capacitor will limit the values of the droop gain

$$
K<\frac{C_{\mathrm{bus}} \cdot \omega_{c l}}{\alpha} .
$$

The droop gain $K$ will generate, at nominal current, deviations in the dc bus voltage equal in per unit to

$$
\delta=\frac{P_{n}}{K \cdot V_{\mathrm{dc}}^{2}} .
$$

From these expressions, it can be observed that if the dc bus capacitor has been chosen too small, then (5) imposes a boundary that is too tight for $K$, resulting in extremely large values for $\delta$. Of course, this is not allowable in a real system. As seen in [30] and [31], values around 0.05 are typically chosen for $\delta$. Having a value imposed for $\delta$, the value of the dc bus capacitor can be computed by

$$
C_{\mathrm{bus}}=\frac{\alpha \cdot P_{n}}{\delta \cdot \omega_{c l} \cdot V_{\mathrm{dc}}^{2}}
$$

\section{Simulation Results}

The simulation scenarios were chosen considering the operation of a PV-based power plant in the range of $100 \mathrm{~kW}$ that integrates ES. The operating voltage of the network was chosen at $685 \mathrm{~V}$. For all the converters connected to the network the switching frequency was considered to be $10 \mathrm{kHz}$. Also, the time constant of the internal current loops was considered to be equal to 6 switching periods. Choosing $\delta=0.05$ will require a $\mathrm{NO}$ band of $70 \mathrm{~V}$ for the network. The width of the safety and critical band was fixed to $14 \mathrm{~V}$. As the size of the output capacitor is influenced by the speed of the internal current loop and $\delta$, capacitors of $4.8 \mathrm{mF}$ were used for all the elements connected to the dc bus.

\section{A. Scenario 1-Basic System. Energy-Storage Discharge}

As can be seen in Fig. 5, in this study-case three power converters are connected to a common dc bus. Converter 1 is a boost converter controlled by a bidirectional droop and connects a battery with a storing capacity of 30 minutes at nominal power. The $\mathrm{SoC}$ operating intervals needed for defining the droop characteristic were ideally selected as: $S o C_{l 2}=5 \%, S o C_{l 1}=20 \%$, $S o C_{h 1}=80 \%, S o C_{h 2}=95 \%$. 


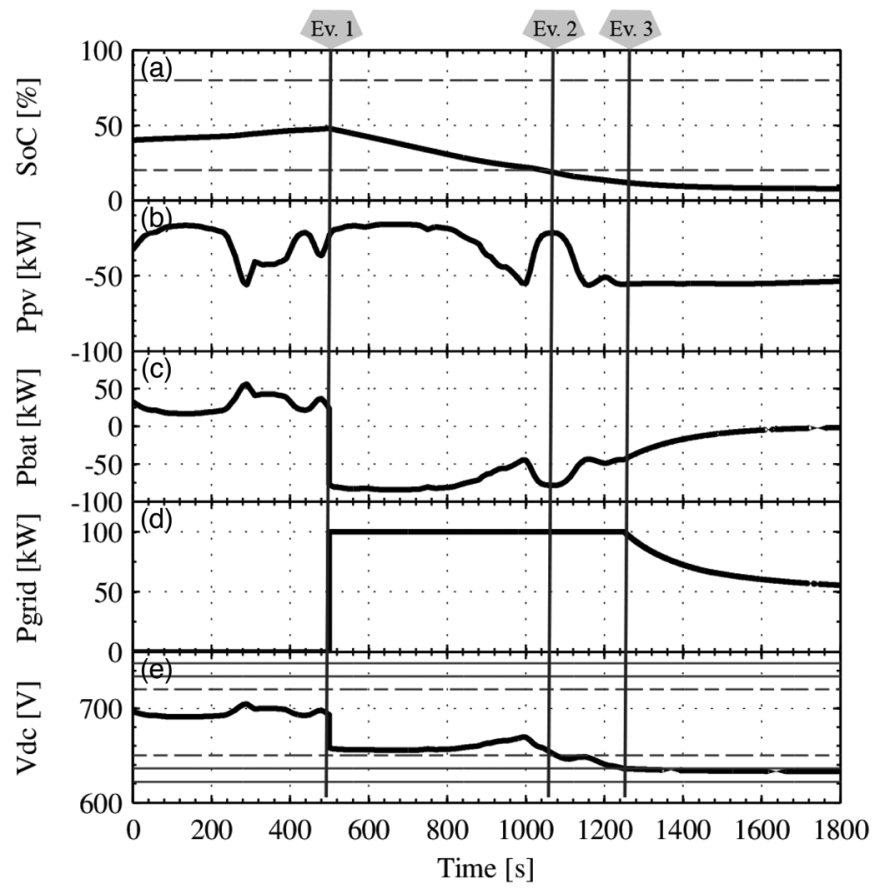

Fig. 6. Simulation Scenario 1. Basic system. Discharge of the ES: (a) State of charge of the ES (in percentage). (b) Power production of the PV plant (in $\mathrm{kW}$ ). (c) Power imported/exported by the ES (in kW). (d) Power injected to the ac-grid (in $\mathrm{kW}$ ). (e) DC bus voltage and the operating bands (in volts).

A PV power plant rated at $100 \mathrm{~kW}$ is connected to the common dc bus by converter 3. A real irradiance profile was used in order to emulate the hectic behavior of the PV production. Finally, the system is connected through a noncritical connection to the ac-grid by means of a $100 \mathrm{~kW} \mathrm{dc-ac} \mathrm{con-}$ verter-converter 1 .

The proposed scenario starts with the battery charged at $40 \%$ of the maximum capacity and converter 1 disconnected. The determination of the state of charge of the battery was based on the method of current integration. The average PV production is around $40 \mathrm{~kW}$, but large deviations from this value, typical for the PV generation, can be observed. Since initially converter 1 is disconnected, all the power produced by the PV goes into the batteries, increasing the SoC, visible in Fig. 6(a).

Fig. 6 shows the signals of interest for the described scenario. The key events are highlighted by a vertical guideline, completed with a grey pentagonal marker at the top of the figure.

Event 1 (Ev. 1) - ac-grid converter is enabled. A reference of $100 \mathrm{~kW}$ is set for converter 1 as can be seen in Fig. 6(d). Since the PV output, see Fig. 6(b), is not sufficient to satisfy this demand, the battery has to compensate for the difference and starts discharging as can be seen in Fig. 6(a) and (c). A large drop in the dc bus voltage, proportional with the droop resistance can be noted in Fig. 6(e), but the voltage is kept between the normal operation limits.

Event 2 (Ev. 2)-battery SoC reaches $\mathbf{2 0 \%}$. This corresponds to $S o C_{l 1}$. Now, according to the dependence of the droop characteristic on the $\mathrm{SoC}$, as the battery continues discharging, the connected converter linearly shifts downwards its dc voltage operating point. Since there is only one energy-storage unit connected to the system, further discharge

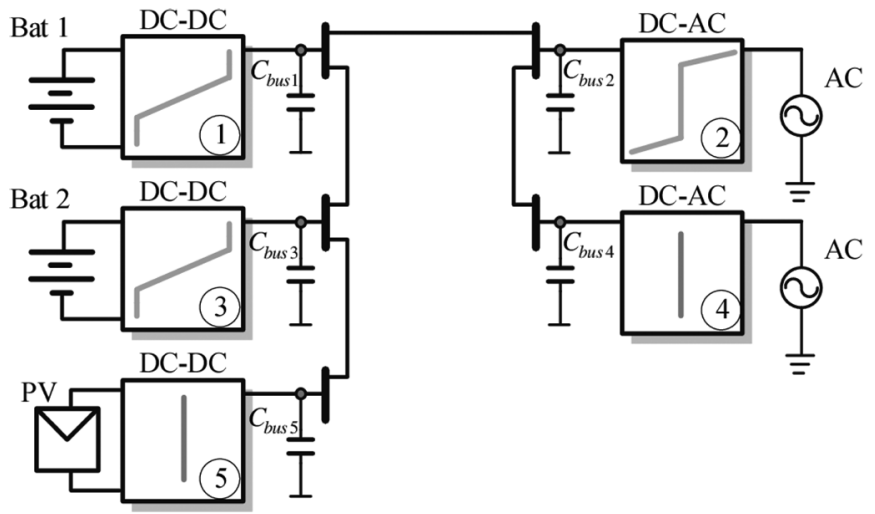

Fig. 7. Block diagram of Simulation Scenario 2. Extended system composed of two bidirectional ESs, one critical PV generator, and two ac grid connections (one critical and one pseudocritical).

will result in a linear decrease of the dc bus voltage, as seen in Fig. 6(e).

Event 3 (Ev. 3) - de bus voltage reaches CL band. As the battery continues to discharge, the dc bus voltage reaches the critical low band as seen in Fig. 6(e). Since the ac connection is pseudocritical, the injected power starts to deviate automatically from the reference in order to maintain the power balance of the system, as seen in Fig. 6(d). Finally, the battery power is reduced to zero as the battery is getting close to $S o C_{l 2}$. Meanwhile, the power produced by the PV is injected into the ac grid. In such a case, the secondary control could choose to dispatch the energy in a different manner, and decide to charge the battery instead of supplying the noncritical load.

\section{B. Scenario 2-Extended System. Energy-Storage Discharge}

The second scenario expands the previous one by connecting two extra converters to the common dc bus. The previous 30 minutes storage unit is split in this experiment in two battery banks of 20 minutes (Bat1) and 10 minutes (Bat2), respectively. The two battery banks are interfaced by two bidirectional dc-dc converters. In addition, the $100 \mathrm{~kW}$ pseudocritical ac-grid connection has been replaced by two connections - one critical (converter 4) and one pseudocritical (converter 2) as seen in Fig. 7.

As previously, the system starts with converter 2 and 4 disabled, and the two batteries being charged by the production of the PV. The initial state of charge of the two batteries is $60 \%$ for Bat 1 and $40 \%$ for Bat 2 . The evolution of the signals of interest can be observed in Fig. 8. As previously, the key events are highlighted at the top of the figure.

Event 1 (Ev. 1) - ac-grid converters are enabled. A reference of $50 \mathrm{~kW}$ is set for converter 4 and a reference of $45 \mathrm{~kW}$ for converter 2, as seen in Fig. 8(d). Since the PV output is not sufficient to cover the power demand, the two batteries have to compensate for the difference. Both batteries have sufficient energy and the load is equally shared between the two converters [Fig. 8(c)].

Event 2 (Ev. 2)-SoC of Bat2 reaches 20\%. Besides having a smaller capacity, Bat 2 also starts with a smaller SoC, hence it reaches the lower threshold of $20 \%$ faster, as seen in Fig. 8(a). As a result, converter 3 will start to shift its operating voltage 


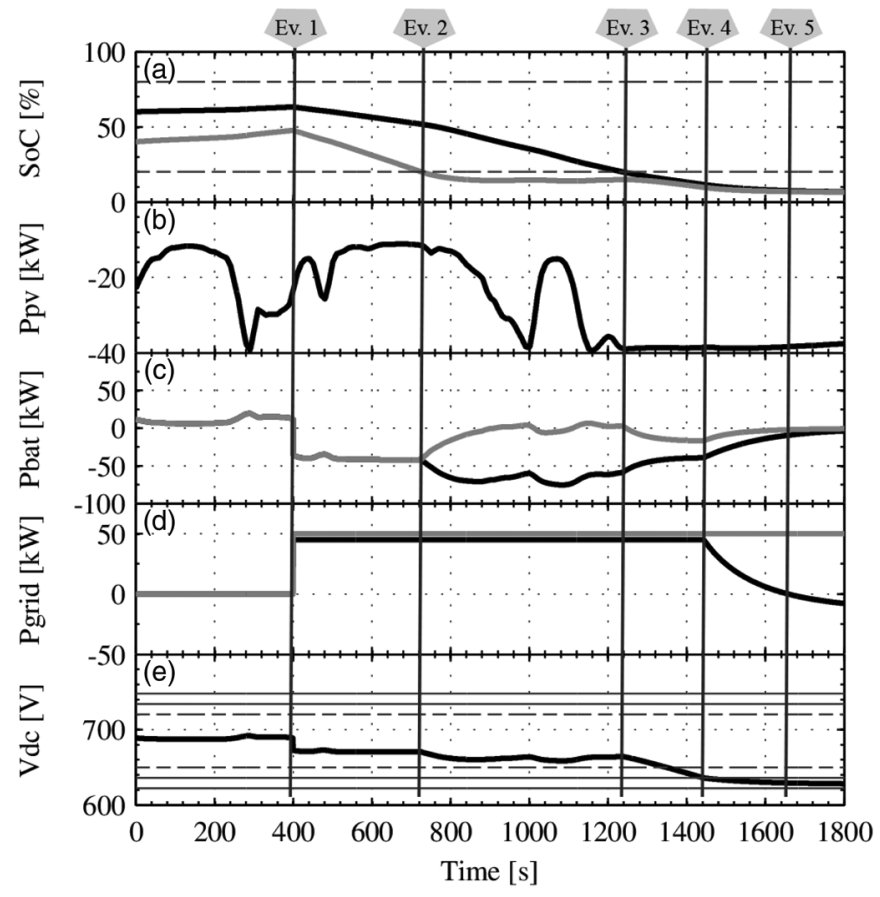

Fig. 8. Simulation Scenario 2. Extended system. Discharge of the ES. (a) State of charge of the ES (in percentage). (b) Power production of the PV plant (in $\mathrm{kW}$ ). (c) Power imported/exported by the ES (in kilowatts). (d) Power injected by the ac grid converters (in kilowatts). (e) DC bus voltage and the operating bands (in volts).

downwards yielding a reduction of the power output as seen in Fig. 8(c). Bat1 still has sufficient energy and it will automatically compensate this change. Because there is still one battery remaining between normal $\mathrm{SoC}$ limits, the system continues to operate in the NO band, as it can be seen in Fig. 8(e)

Event 3 (Ev. 3)-SoC of Bat1 reaches $20 \%$. Bat1 also reaches $S_{o} C_{l 1}$ and converter 1 starts to shift its operating voltage according to the implemented droop characteristic. This time there is no other element in the network to maintain the dc bus voltage in the normal operating band, hence it decreases slowly into the safety band, as seen in Fig. 8(e).

Event 4 (Ev. 4)-dc bus voltage reaches $C L$ band. The dc bus reaches the critical low limit. At this point, the power output of the energy-storage units is severely limited and the PV production is not sufficient to supply both loads. Under these circumstances, the noncritical grid connection starts to reduce its power output in order to avoid the collapse of the system. As it can be seen in Fig. 8(d), the reference of $50 \mathrm{~kW}$ for converter 4 is still entirely fulfilled, while the reference for converter 2 starts to deviate from its scheduled value. The dc bus voltage is now signaling an overloaded mode of operation.

Event 5 (Ev. 5) - inversion of power direction. If the droop characteristic allows it, the noncritical grid connection can pass from consuming power to injecting power in order to supply the requirement of the critical load, as seen in Fig. 8(d).

\section{EXPERIMENTAL RESULTS}

In order to validate the simulation results, a scaled prototype was assembled in our laboratory. According to Table I, three elements were connected to a common $685 \mathrm{~V}$ dc bus system.
TABLE I

PARAMETERS OF THE EXPERIMENTAL SETUP

\begin{tabular}{|c|c|c|c|}
\hline \multicolumn{3}{|r|}{ Description } & Value \\
\hline \multirow{4}{*}{$\begin{array}{l}0 \\
\text { Ũ } \\
\text { Un }\end{array}$} & $P_{n}$ & nominal power & $10[\mathrm{~kW}]$ \\
\hline & $V_{d c}$ & dc-bus voltage & $685[\mathrm{~V}]$ \\
\hline & $V_{\text {bat }}$ & battery voltage & $200[\mathrm{~V}]$ \\
\hline & $f_{s}$ & switching frequency & $10[\mathrm{kHz}]$ \\
\hline \multirow{3}{*}{$\begin{array}{l}\tilde{J} \\
\dot{J} \\
\text { J }\end{array}$} & $P_{n}$ & nominal power & $10[\mathrm{~kW}]$ \\
\hline & $V_{d c}$ & dc-bus voltage & $685[\mathrm{~V}]$ \\
\hline & $f_{s}$ & switching frequency & $10[\mathrm{kHz}]$ \\
\hline \multirow{4}{*}{ 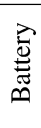 } & \multicolumn{3}{|c|}{ Sprinter - P12V600 Lead Acid } \\
\hline & $V_{n}$ & nominal unit voltage & $12[\mathrm{~V}]$ \\
\hline & $C_{n}$ & nominal capacity & 24 [Ah] \\
\hline & \multicolumn{3}{|c|}{ The battery bank contains 17 units connected in series } \\
\hline \multirow{2}{*}{ a } & $P_{n}$ & nominal power & $10[\mathrm{~kW}]$ \\
\hline & \multicolumn{3}{|c|}{ emulated using real irradiation data for a Regatron power source } \\
\hline
\end{tabular}

The energy-storage element, a 24 Ah lead acid battery, was connected through a three-phase interleaved boost dc-dc converter controlled by the dSpace 1103 unit. The interleaved topology was used because a faster current loop can be achieved as a result of the reduced inductor size. The $10 \mathrm{~kW}$ ac grid connection was realized through a 2 level dc-ac converter, also controlled by the dSpace 1103 . Finally, the PV was emulated by programming a real irradiance profile in a current controlled Regatron power source. In this experiment the height of the $\mathrm{NO}$ band for the droop controller was fixed to $32 \mathrm{~V}$ by imposing a $\delta$ of 0.0115 . The critical bands and the safety bands were chosen equal to half of the normal operation one.

While performing tests for determining the behavior of the batteries we observed increased power sensitivity at low or high SoC. However, this is a well-known effect in lead-acid batteries according to [32]. Therefore, the limits of $5 \%$ and $95 \%$ used in simulation were impracticable due to the small amount of power that the battery is able to provide, respectively absorb at these levels. The following limits were chosen for the practical usage of the lead-acid battery: $S o C_{l 2}=30 \%, S o C_{l 1}=45 \%$, $S o C_{h 1}=60 \%, S o C_{h 2}=75 \%$.

\section{A. Scenario 1-Energy-Storage Discharge}

The first study case investigates the self-management capability of the system when the battery is discharging. The experiment starts with the battery charged at $50 \%$, and the grid converter disconnected. Therefore, all the power produced by the PV goes into the batteries, increasing the $\mathrm{SoC}$, visible in Fig. 9(a). Fig. 9 shows the signals of interest for the described scenario and highlights the key events that are detailled in the following paragraphs.

Event 1 (Ev. 1)-ac-grid converter is enabled. The ac grid converter is enabled and a reference of $8 \mathrm{~kW}$ is set as seen in Fig. 9(d). Since the PV output, Fig. 9(b), is not sufficient to satisfy this demand, the battery has to compensate for the difference and starts discharging as seen in Fig. 9(a) and (c). A drop in the dc bus voltage proportional with the droop resistance can be noted in Fig. 9(e), but the voltage is kept between the normal operation limits.

Event 2 (Ev. 2)-PV power fluctuation. Fluctuations in the PV production, seen in Fig. 9(b), are compensated entirely by the battery while the system is in the normal operation band.

Event 3 (Ev. 3)-battery SoC reaches $45 \%$. The SoC of the battery reaches the first limit and since the discharge continues, 


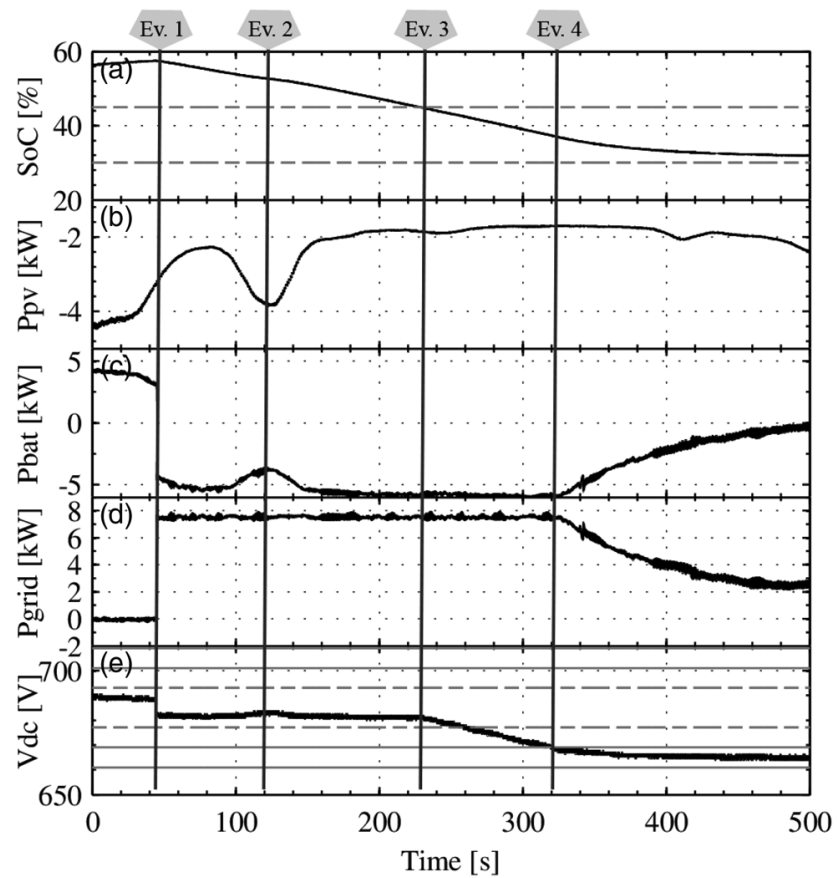

Fig. 9. Experimental Scenario 1. Basic system. Discharge of the ES. (a) State of charge of the ES (in percentage). (b) Power production of the PV plant (in kilowatts). (c) Power imported/exported by the ES (in kilowatts). (d) Power injected by the ac grid converter (in kilowatts). (e) DC bus voltage and the operating bands (in volts).

the converter linearly shifts its droop characteristic bringing the dc bus voltage level towards the safety low band. The dc bus voltage is now signaling the reduced level of energy remaining in the battery.

Event 4 (Ev. 4) - dc bus voltage reaches $C L$ band. The dc bus voltage reaches the critical low band, as seen in Fig. 9(e). At this point, according to its droop characteristics, the pseudocritical grid connection starts to reduce its power demand, as shown in Fig. 9(d). The dc bus voltage is signaling now an overloaded mode of operation.

\section{B. Scenario 2-Energy-Storage Charge}

The second scenario, presented in Fig. 10, investigates the behavior of the system when the battery is charging. As before, the initial SoC of the battery is $50 \%$ and the ac grid converter is disabled. The PV production is charging the battery. The events highlighted in Fig. 10 are detailed in the following paragraphs.

Event 1 (Ev. 1) - ac-grid converter is enabled. The ac-grid converter is enable and a reference of $-2.8 \mathrm{~kW}$ is set, as shown in Fig. 10(c). Since the grid converter and PV are injecting power into the dc bus, the rate of charge of the battery increases in order to maintain the system in equilibrium, as seen in Fig. 10(a) and (c). An increase in the dc bus voltage level, proportional to the droop value, is seen in Fig. 10(e) at the moment of connection, but the final value is inside the NO band.

Event 2 (Ev. 2)-battery SoC reaches $60 \%$. The SoC of the battery, shown in Fig. 10(a), reaches the $60 \%$ limit. Since the charge continues, the converter linearly shifts upward its droop characteristic, bringing the dc bus voltage toward the critical high band as seen in Fig. 10(e).

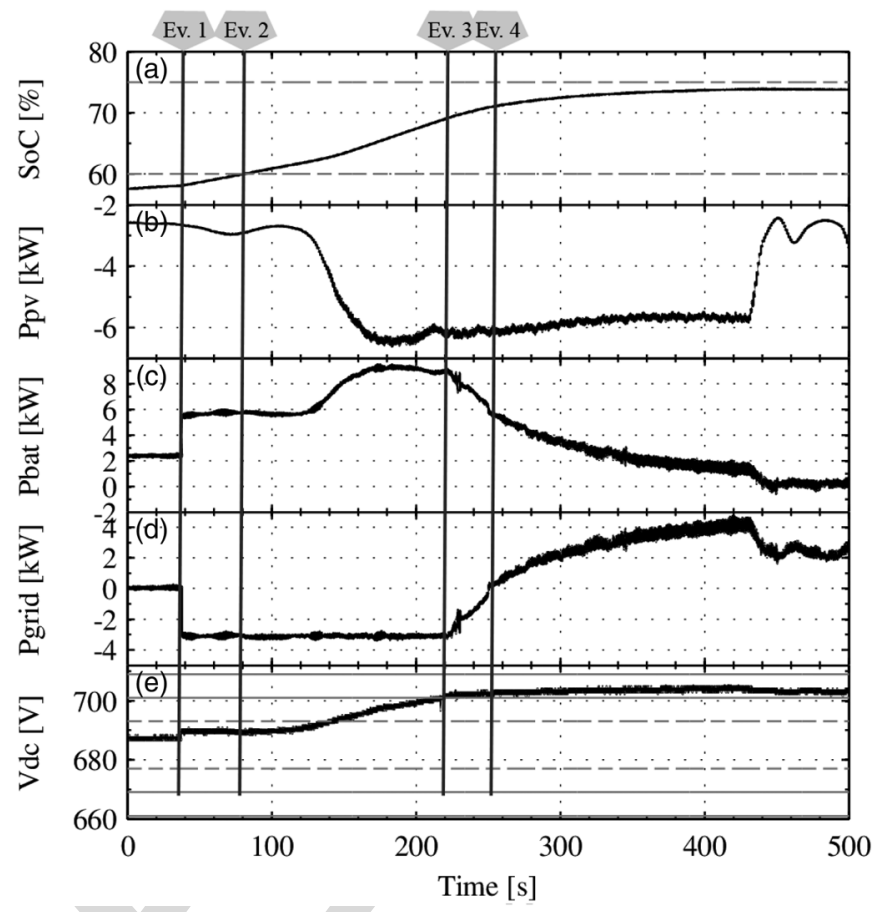

Fig. 10. Experimental Scenario 2. Basic system. Charge of the ES. (a) State of charge of the ES (in percentage). (b) Power production of the PV plant (in kilowatts). (c) Power imported/exported by the ES (in kilowatts). (d) Power injected by the ac grid converter (in kilowatts). (e) DC bus voltage and the operating bands (in volts).

Event 3 (Ev. 3)-dc bus voltage reaches CH band. The dc bus voltage reaches the critical high band. Since the grid converter is controlled as a pseudocritical element, it will automatically start to decrease the power injected into the dc bus as seen in Fig. 10(d). At this point, the limitation of the power injected into the battery becomes obvious in Fig. 10(c).

Event 4 (Ev. 4)-inversion of power direction. Since the droop of the grid converter is bidirectional, it allows for the converter to change the sign of its reference. As shown in Fig. 10(d)., the grid converter changes independently from charging the dc bus to loading it in order to avoid an overvoltage situation.

\section{CONCLUSION}

The integration of energy storage, together with renewable sources into MTDC networks, could be the most feasible solution for the problem of large-scale penetration of renewable energy, especially if the ancillary services that these generation facilities should provide are considered. However, as can be seen from the literature survey, the control strategies for such systems are mainly application specific and still far away from a standardized approach.

While supporting the idea of a hierarchical control strategy for MTDC networks, this paper proposes a decentralized primary control layer obtained by combining two methodologies for distributed dc bus control, namely, droop and dc bus signaling control. The simulation and experimental results have shown that building custom droops around various operating bands introduces more flexibility at the primary control level. 
The proposed control strategy pays specific attention to the integration of energy storage into MTDC systems and it includes the operating conditions of the ES elements in the design of the control. Thus, a new droop surface is obtained by taking into account the SoC of the storage and the dc bus voltage level. This feature allows the primary control layer to better handle the energy stored in the dc network, and it adapts the control profile in order to prevent overcharges and deep discharges in the storage elements.

In order to validate the proposed solution, simulations were performed on a $100 \mathrm{~kW}$ system incorporating PV generation, two energy-storage devices and two parallel connections to the ac grid. The obtained results confirm the viability of the system throughout the different operating modes. Further on, experimental studies were performed on a scaled $10 \mathrm{~kW}$ laboratory prototype composed of an energy-storage element, a PV generator and one connection to the ac grid. The same behavior observed in simulation was reproduced by the experimental results, thus confirming the potential of the proposed solution to operate as a basic framework for a hierarchical control architecture for an MTDC network.

\section{REFERENCES}

[1] N. R. Chaudhuri and B. Chaudhuri, "Adaptive droop control for effective power sharing in Multi-Terminal DC (MTDC) grids," IEEE Trans. Power Syst., vol. 28, no. 1, pp. 21-29, Feb. 2013.

[2] C. Dierckxsens, K. Srivastava, M. Reza, S. Cole, J. Beerten, and R. Belmans, "A distributed DC voltage control method for VSC MTDC systems," Elect. Power Syst. Res., vol. 82, no. 1, pp. 54-58, Jan. 2012

[3] T. M. Haileselassie and K. Uhlen, "Precise control of power flow in multiterminal VSC-HVDCs using DC voltage droop control," in Proc. IEEE Power Energy Soc. Gen. Meeting, 2012, pp. 1-9.

[4] R. da Silva, R. Teodorescu, and P. Rodriguez, "Multilink DC transmission system for supergrid future concepts and wind power integration," in Proc. IET Conf. Renew. Power Gen., 2011, pp. 1-6.

[5] O. Gomis-Bellmunt, J. Liang, J. Ekanayake, R. King, and N. Jenkins, "Topologies of multiterminal HVDC-VSC transmission for large offshore wind farms," Elect. Power Syst. Res., vol. 81, no. 2, pp. 271-281, Feb. 2011.

[6] K. Meah and A. H. M. S. Ula, "A new simplified adaptive control scheme for multi-terminal HVDC transmission systems," Int. J. Elect. Power Energy Syst., vol. 32, no. 4, pp. 243-253, May 2010.

[7] L. Xu, B. W. Williams, and L. Yao, "Multi-terminal DC transmission systems for connecting large offshore wind farms," in Proc. IEEE Power Energy Soc. Gen. Meeting-Convers. Del. Elect. Energy 21st Century, 2008, pp. 1-7.

[8] N. R. Chaudhuri, R. Majumder, B. Chaudhuri, and J. Pan, "Stability analysis of VSC MTDC grids connected to multimachine AC systems," IEEE Trans. Power Del., vol. 26, no. 4, pp. 2774-2784, Oct. 2011.

[9] G. O. Kalcon, G. P. Adam, O. Anaya-Lara, S. Lo, and K. Uhlen, "Small-signal stability analysis of multi-terminal VSC-based DC transmission systems," IEEE Trans. Power Syst., vol. 27, no. 4, pp. 1818-1830, Nov. 2012

[10] S. Cole, J. Beerten, and R. Belmans, "Generalized dynamic VSC MTDC model for power system stability studies," IEEE Trans. Power Syst., vol. 25, no. 3, pp. 1655-1662, Jul. 2010.

[11] M. E. Baran and N. R. Mahajan, "Overcurrent protection on voltagesource-converter-based multiterminal DC distribution systems," IEEE Trans. Power Del., vol. 22, no. 1, pp. 406-412, Jan. 2007.

[12] L. Tang and B.-T. Ooi, "Locating and isolating DC faults in multiterminal DC systems," IEEE Trans. Power Del., vol. 22, no. 3, pp. 1877-1884, Jul. 2007.

[13] J. Yang, J. E. Fletcher, and J. O'Reilly, "Multiterminal DC wind farm collection grid internal fault analysis and protection design," IEEE Trans. Power Del., vol. 25, no. 4, pp. 2308-2318, Oct. 2010.

[14] J. Yang, J. E. Fletcher, and J. O'Reilly, "Short-circuit and ground fault analyses and location in VSC-based DC network cables," IEEE Trans. Ind. Electron., vol. 59, no. 10, pp. 3827-3837, Oct. 2012.
[15] O. Nanayakkara, A. D. Rajapakse, and R. Wachal, "Traveling-wavebased line fault location in star-connected multiterminal HVDC systems," IEEE Trans. Power Del., vol. 27, no. 4, pp. 2286-2294, Oct. 2012.

[16] B. Silva, C. L. Moreira, L. Seca, Y. Phulpin, and J. A. P. Lopes, "Provision of inertial and primary frequency control services using offshore multiterminal HVDC networks," IEEE Trans. Sustain. Energy, vol. 3, no. 4, pp. 800-808, Oct. 2012.

[17] J. Dai, Y. Phulpin, A. Sarlette, and D. Ernst, "Coordinated primary frequency control among non-synchronous systems connected by a multi-terminal high-voltage direct current grid," IET Gen., Transm. Distrib., vol. 6, no. 2, pp. 99-108, 2012.

[18] T. M. Haileselassie and K. Uhlen, "Primary frequency control of remote grids connected by multi-terminal HVDC," in Proc. IEEE Power Energy Soc. Gen. Meeting, 2010, pp. 1-6.

[19] T. M. Haileselassie and K. Uhlen, "Frequency sensitivity analysis of ac grids connected to MTDC grid," in Proc. 9th IET Int. Conf. AC DC Power Transm., 2010, pp. 1-5.

[20] K. Sun, L. Zhang, Y. Xing, and J. M. Guerrero, "A distributed control strategy based on DC bus signaling for modular photovoltaic generation systems with battery energy storage," IEEE Trans. Power Electron., vol. 26, no. 10, pp. 3032-3045, Oct. 2011.

[21] X.-P. Zhang, "Multiterminal voltage-sourced converter-based HVDC models for power flow analysis," IEEE Trans. Power Syst., vol. 19, no. 4, pp. 1877-1884, Nov. 2004.

[22] J. Bryan, R. Duke, and S. Round, "Decentralized generator scheduling in a nanogrid using DC bus signaling," in Proc. IEEE Power Eng. Soc. Gen. Meeting, 2004, vol. 1, pp. 977-982.

[23] K. Kurohane, A. Uehara, T. Senjyu, A. Yona, N. Urasaki, T. Funabashi, and C.-H. Kim, "Control strategy for a distributed DC power system with renewable energy," Renew. Energy, vol. 36, no. 1, pp. 42-49, Jan. 2011.

[24] J. Schonberger, R. Duke, and S. D. Round, "DC-bus signaling: A distributed control strategy for a hybrid renewable nanogrid," IEEE Trans. Ind. Electron., vol. 53, no. 5, pp. 1453-1460, Oct. 2006.

[25] D.-C. Lu and V. G. Agelidis, "Photovoltaic-battery-powered DC bus system for common portable electronic devices," IEEE Trans. Power Del., vol. 24, no. 3, pp. 849-855, Jul. 2009.

[26] K. Kurohane, T. Senjyu, A. Yona, N. Urasaki, T. Goya, and T. Funabashi, "A hybrid smart AC/DC power system," IEEE Trans. Smart Grid, vol. 1, no. 2, pp. 199-204, Sep. 2010.

[27] J. M. Guerrero, J. C. Vasquez, J. Matas, L. G. de Vicuna, and M. Castilla, "Hierarchical control of droop-controlled AC and DC microgrids-A general approach toward standardization," IEEE Trans. Ind. Electron., vol. 58, no. 1, pp. 158-172, Jan. 2011

[28] N. Mohan, T. M. Underland, and W. P. Robbins, Power Electronics. Converters, Applications and Design. New York, USA: Wiley, 1989.

[29] S. Buso and P. Mattavelli, Digital Control in Power Electronics, J. Hudgins, Ed. : University of Nebraska-Lincoln: Morgan\&Claypool, 2006/Please provide location of publisher]

[30] L. Xu and L. Yao, "DC voltage control and power dispatch of a multiterminal HVDC system for integrating large offshore wind farms," IET Renew. Power Gen., vol. 5, no. 3, pp. 223-233, 2011.

[31] P. Karlsson and J. Svensson, "DC bus voltage control for a distributed power system," IEEE Trans. Power Electron., vol. 18, no. 6, pp. 1405-1412, Nov. 2003.

[32] D. Linden, Handbook of Batteries, 3rd ed. New York, USA: McGraw-Hill, 2002.

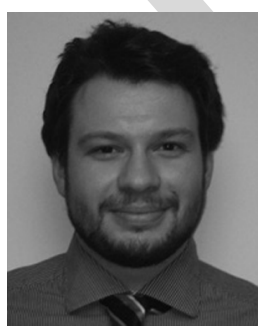

Catalin Gavriluta (S'13) was born in Arad, Romania, in 1986. He received the M.Sc. degree in wind power systems from Aalborg University, Aalborg, Denmark, in 2011 and is currently pursuing the Ph.D. degree [Author: in what field?] at the Technical University of Catalunya, Catalunya, Spain.

Prior to that, he graduated with a five-years Engineering study program in Automation and Applied Informatics from "Politehnica" University of Timisoara, Timisoara,, Romania. Since 2011, he has been enrolled as a Researcher at the Technical University of Catalunya, Catalunya, Spain. His work and interests are oriented toward the control and operation of MTDC networks used for large-scale integration of solar power supported by energy storage. 


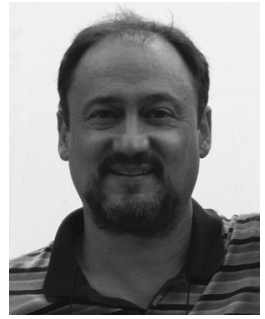

J. Ignacio Candela (S'99-M'04) received the B.S. and M.S. degrees in industrial engineering and the $\mathrm{Ph} . \mathrm{D}$. degree in electrical engineering from the Technical University of Catalunya (UPC), Barcelona, Spain, in 1987, 2000, and 2009, respectively.

In 1990, he became an Assistant Professor at UPC, where he later advanced to Associate Professor in 1993. Currently, he is part of the research group on Renewable Electrical Energy Systems, Department of Electrical Engineering. He has authored or coauthored more than 30 published technical papers, and holds several patents. His current research interests include power conditioning, integration of distributed energy systems, and the control of grid-connected power converters.

Dr. Candela is a member of the IEEE Power Electronics Society, the IEEE Industrial Electronics Society, and the IEEE Industry Application Society.

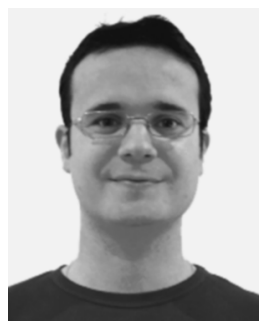

Joan Rocabert (S'08-M'11) was born in Barcelona, Spain. He received the M.Sc. degree in electrical engineering and the Ph.D. degree in electrical engineering on the topic of PV microgrids control from the Technical University of Catalunya (UPC), Barcelona, Spain, in 2003 and 2010, respectively.

From 2004 to 2008, he was a Research Assistant in the Department of Electronic Engineering, UPC. Since 2008, he has been with the Department of Electrical Engineering, working as a Researcher and Assistant Professor. His current research interests include power electronics applied to energy storage as well as photovoltaic and wind energy systems, particularly their applications toward microgrids.

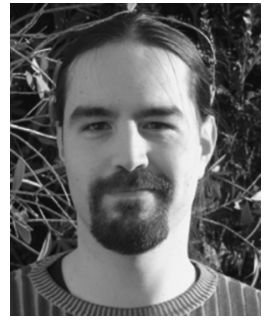

Alvaro Luna (S'07-M'10) received the B.Sc., M.Sc., and Ph.D. degrees in electrical engineering from the Technical University of Catalunya (UPC), Barcelona, Spain, in 2001, 2005, and 2009, respectively.

He joined the faculty of UPC in 2005, where he is currently an Assistant Professor. His research interests include wind turbines control, integration of distributed generation, and power conditioning.

Mr. Luna is member of the IEEE Power Elecciety, and the IEEE Industrial Applications Society.

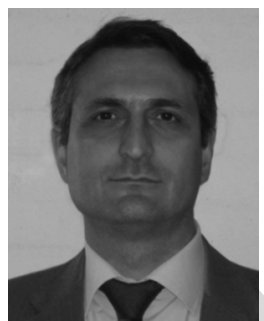

Pedro Rodriguez (S'99-M'04-SM'10-F'13) received the M.Sc. and Ph.D. degrees in electrical engineering from the Technical University of Catalunya (UPC), Barcelona, Spain, in 1994 and 2004, respectively.

He was a Postdoctoral Researcher at the Center for Power Electronics Systems (CPES), Virginia Polytechnic Institute and State University, Blacksburg, VA, USA, in 2005, and at the Department of Energy Technology, Aalborg University (AAU), Aalborg, Denmark, in 2006. He joined the faculty of UPC as an Assistant Professor in 1990, where he became the Director of the Research Center on Renewable Electrical Energy Systems (SEER) in the Department of Electrical Engineering. He is currently linked to the UPC as a Part-Time Professor. He was also a Visiting Professor at AAU from 2007 to 2011, acting as a Co-Supervisor of the Vestas Power Program. He still lectures $\mathrm{Ph} . \mathrm{D}$. courses at the AAU every year. In 2011, he joined Abengoa, where he is currently the Director of Technology on Power Systems and Power Electronics. He has coauthored one book and more than 200 papers in technical journals and conference proceedings. He is the holder of nine licensed patents. His research interests include distributed power systems, flexible transmission systems, and power conversion.

Dr. Rodriguez is the Vice-Chair of the Sustainability and Renewable Energy Committee of the IEEE Industry Application Society and a member of the IEEE-IES Technical Committee on Renewable Energy Systems. He is an Associate Editor of the IEEE TRANSACTIONS ON POWER ELECTRONICS. 